\title{
Folic Acid Modulates Matrix Metalloproteinase-2 Expression, Alleviates Neuropathic Pain, and Improves Functional Recovery in Spinal Cord-Injured Rats
}

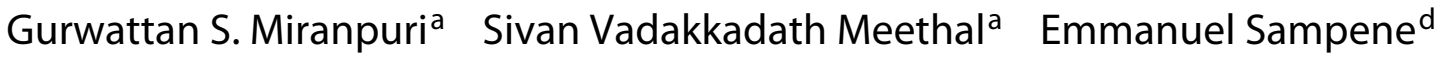 \\ Abhishek Chopra $^{a}$ Seah Buttar ${ }^{a}$ Carrie Nacht ${ }^{a} \quad$ Neydis Moreno $^{a} \quad K_{\text {Ksh Patel }}{ }^{a}$ \\ Lisa Liu $^{a}$ Anupama Singh ${ }^{b}$ Chandra K. Singh ${ }^{c}$ Nithya Hariharan ${ }^{a}$ \\ Bermans Iskandar ${ }^{a}$ Daniel K. Resnick ${ }^{a}$ \\ a Department of Neurological Surgery, University of Wisconsin School of Medicine and Public Health, \\ ${ }^{b}$ Department of Human Oncology, ${ }^{C}$ Department of Dermatology, and ${ }^{\mathrm{d}}$ Department of Biostatistics and \\ Mathematical Informatics, University of Wisconsin, Madison, WI, USA
}

\section{Keywords}

Contusion spinal cord injury - Thermal hyperalgesia .

Neuropathic pain - Matrix metalloproteinase $\cdot$ Matrix

metalloproteinase $\cdot$ Matrix metalloproteinase $2 \cdot$ Folic acid .

DNA methylation

\begin{abstract}
Background: The molecular underpinnings of spinal cord injury $(\mathrm{SCl})$ associated with neuropathic pain (NP) are unknown. Recent studies have demonstrated that matrix metalloproteinases (MMPs) such as MMP2 play a critical role in inducing NP following $\mathrm{SCl}$. Promoter methylation of MMPs is known to suppress their transcription and reduce NP. In this context, it has been shown in rodents that folic acid (FA), an FDA approved dietary supplement and key methyl donor in the central nervous system (CNS), increases axonal regeneration and repair of injured CNS in part via methylation. Purpose: Based on above observations, in this study, we test whether FA could decrease MMP2 expression and thereby decrease SCl-induced NP. Methods: Sprague-Dawley male rats weighing 250-270 g received contusion spinal cord injuries ( $\mathrm{CSCls}$ ) with a custom spinal cord impactor device that
\end{abstract}

๑) 2017 S. Karger AG, Basel drops a $10 \mathrm{~g}$ weight from a height of $12.5 \mathrm{~mm}$. The injured rats received either i.p. injections of FA $(80 \mu \mathrm{g} / \mathrm{kg})$ or water (control) 3 days prior and 17 days post- $\mathrm{cSCl}$ (mid phase) or for 3 days pre- $\mathrm{CSCl}$ and 14 days post-cSCl ending on the $42 \mathrm{nd}$ day of $\mathrm{CSCl}$ (late phase). The functional neurological deficits due to $\mathrm{CSCl}$ were then assessed by Basso, Beattie, and Bresnahan (BBB) scores either on post-impaction days 0 through 18 post- $\mathrm{CSCl}$ (mid phase) or on days $0,2,7,14,21$, 28,35 , and 42 (late phase). Baseline measurements were taken the day before starting treatments. Thermal hyperalgesia (TH) testing for pain was performed on 4 days pre-cSCl (baseline data) and on days 18, 21, 28, 35, and 42 post-cSCl. Following $\mathrm{TH}$ testing, animals were euthanized and spinal cords harvested for MMP-2 expression analysis. Result: The FA-treated groups showed higher BBB scores during mid phase (day 18) and in late phase (day 42) of injury compared to controls, suggesting enhanced functional recovery. There is a transient decline in TH in animals from the FA-treated group compared to controls when tested on days $18,21,28$, and 35 , indicative of a decrease in NP. However, when tested

G.S.M. and S.V.M. contributed equally.

\section{KARGER}

E-Mail karger@karger.com

www.karger.com/aon
Daniel K. Resnick, MD, MS

Department of Neurological Surgery

University of Wisconsin School of Medicine and Public Health

K4/834 Clinical Science Center, 600 Highland Ave, Madison, WI 53792 (USA)

E-Mail resnick@neurosurgery.wisc.edu 
25 days after stopping FA administration on day 42 of $\mathrm{CSCl}$, no significant difference in $\mathrm{TH}$ was observed between FA-treated and control animals. Western blot analysis of the injured spinal cord from FA-treated animals showed significant decline in MMP2 expression compared to spinal cord samples from water-treated controls. Conclusion: Together, these data suggest that FA could alleviate NP and improve functional recovery post- $\mathrm{SCl}$, possibly by reducing the expression of MMP2. Further studies will open up a novel and easy natural therapy, ideal for clinical translation with minimal side effects, for managing SCl-induced NP. Such studies might also throw light on a possible epigenetic mechanism in FA-induced recovery after $\mathrm{SCl}$.

(c) 2017 S. Karger AG, Basel

\section{Introduction}

More than 1 million people suffer from spinal cord injury (SCI) in the United States alone, with an additional 12,000 new cases each year. Lack of therapeutic options for mollifying the initial mechanical destruction of tissue and the secondary factors that contribute to total tissue damage in SCI necessitate further investigations of the fundamental mechanisms of SCI-induced neuropathic pain (NP). Recent studies have demonstrated that matrix metalloproteinase (MMPs) such as MMP2 and MMP9 play a critical role in extracellular matrix breakdown and in inducing NP following SCI [1-5]. It has been shown that inhibiting MMP2 and MMP9 significantly decreases $\mathrm{NP}$ in animals that have undergone spinal nerve ligation [1]. However, the underlying mechanisms are unknown. Studies have shown that promoter methylation suppresses the transcription of MMPs and that intrathecal administration of DNA methyl transferase inhibitor following chronic constriction injury (CCI) results in the suppression of global DNA methylation and the methyl-CpGbinding protein $2(\mathrm{MeCP} 2)$ expression, both of which are correlated to a decrease in NP in injured rats [6]. In contrast, SCI results in an increase in global DNA methylation [6]. It is known that hyper methylation of the promotor can silence gene expression [7-10]. In the light of these observations, we hypothesize that possible alterations in DNA methylation pathways might offer promising new therapeutic avenues to alleviate NP and promote functional recovery.

Earlier studies have shown that folic acid (FA), a dietary supplement and the key methylator of the central nervous system (CNS), induces spinal axon regeneration and improves functional recovery after SCI partly via
DNA methylation $[11,12]$. In this paper, we report that FA treatment after injury alters the expression of MMP2, alleviates NP, and improves functional recovery after SCI.

\section{Methods}

Animals

Adult male Sprague-Dawley rats weighing 250-270 g were obtained from Harlan Laboratories, Madison, WI, USA. The SCI and the experiments using animals were conducted with approval from the University of Wisconsin Research Animal Resources and Care Committee and in accordance with published NIH guidelines.

\section{Chemicals}

The source of the chemicals and other materials used in the study are specified wherever they are mentioned in the text.

\section{Drug Administration}

The spinal cord-injured animals were treated intraperitonially with a standardized dose of FA $(80 \mu \mathrm{g} / \mathrm{kg}$ body weight $)[11,12]$ either for 3 days pre-contusion spinal cord injuries (cSCIs) and 17 days post-cSCI (mid phase) or for 3 days pre-cSCI and 14 days post-cSCI ending on the 42 nd day of cSCI (late phase).

\section{Surgery}

We employed a cSCI model to analyze the effect of FA on MMP2 expression and NP.

\section{Contusion SCI}

Sprague-Dawley male rats weighing 250-270 g received cSCI with a custom spinal cord impactor device that drops a $10 \mathrm{~g}$ weight from a height of $12.5 \mathrm{~mm}$ as described earlier [13-20]. Briefly, following the induction of inhalational anesthesia (isoflurane used with oxygen, induction 5\%, maintenance $2.5 \%$ ), T9 laminectomy was performed prior to impaction (online suppl. Fig. 1; for all online suppl.material, seewww.karger.com/doi/10.1159/000475896). Sham control rats also underwent laminectomy without contusion. Manual bladder expression performed on each animal until bladder control was re-established. Representative images showing the extent of SCI via T9 laminectomy demonstrated in online supplementary Figure 1.

\section{Assessment of Functional Outcome}

The functional neurological deficits due to cSCI were assessed by Basso, Beattie, and Bresnahan (BBB) behavioral analysis [21]. Animals were observed individually in an open field testing area consisting of an unfilled plastic wading pool and the BBB scores recorded by a single blinded reviewer either on post-impaction days 0 through 18 post-cSCI (mid phase) or on days $0,2,7,14,21$, 28,35 , and 42 (late phase). Baseline measurements were taken the day before starting treatments.

\section{Assessment of Thermal Hyperalgesia}

Thermal hyperalgesia (TH) testing developed by Hargreaves et al. [22] was used to assess the animal's withdrawal of a hind paw to a thermal noxious stimulus. We have adopted and established this as a sensitive and reliable behavior test as reported previously in several studies [13-20]. Briefly, animals were placed inside the
MMP2 Expression, Alleviates NP, and Improves Functional Recovery in SCI Rats
Ann Neurosci 2017;24:74-81

DOI: $10.1159 / 000475896$ 
Ugo Basile Plantar Test apparatus (Plantar ${ }^{\mathrm{TM}}$ Test, Stoelting, IL, USA) having a focused beam of radiant heat underneath their paws. When each animal moved its paw, a photocell turned off the heat, and the latency to withdraw the paw was recorded. Strength of stimulation was adjusted to produce baseline latencies of 8-10 s (typically $45-47^{\circ} \mathrm{C}$ ). In our standardized TH model, we have found that a decreased withdrawal latency greater than 2-3 s compared to the baseline is an indicator of NP. A safety cutoff of $15 \mathrm{~s}$ was used to prevent prolonged exposure to the noxious heat. Hind limb TH testing was performed the day prior to injury and then again on post-injury days $18,21,28,35$, and 42 . Animals were killed at different experimental time points following injury and the spinal cord harvested for molecular analysis.

Spinal Cord Harvest

Animals were euthanized on days 18 and 42 following injury, and their spinal cords were harvested for MMP2 expression analysis.

\section{Western Blot Analysis}

The spinal cord tissue samples from the epicenter of the injury were lysed in lysis buffer (Sigma Chemical Co., St. Louis, MO, USA) and the protein content determined by Lowry's method [23]. The tissue samples $(30 \mu \mathrm{g} / \mathrm{lane})$ and pre-stained molecular mass markers (Bio-Rad, Hercules, CA, USA) were denatured in SDS reducing buffer (1:2 by volume, Bio-Rad, Hercules, CA, USA) and electrophoresis performed using $12.5 \%$ tris- $\mathrm{HCl}$ gels (Biorad, Hercules, CA, USA). The resolved proteins were then transferred to a polyvinylidene difluoride membrane (PVDF, $0.2 \mu \mathrm{m}$; Bio-Rad, Hercules, CA, USA) and incubated in 5\% non-fat dry milk in trisbuffered saline (TBS) for $30 \mathrm{~min}$. The blot was then incubated overnight at $4{ }^{\circ} \mathrm{C}$ with polyclonal antibody against MMP2 (H-76, 1:500; Santa Cruz Biotechnology, Inc.). The blot was then rinsed in TBS and incubated with corresponding horseradish peroxidaseconjugated secondary IgG (1:2,000; Santa Cruz Biotechnology, CA, USA) for $1.5 \mathrm{~h}$ at room temperature. Bound antibody was visualized using the enhanced chemiluminescent solution (Pierce, Thermo Fisher Scientific, Rockford, IL, USA) as per the manufacturer's instructions. The chemiluminescent signal was captured on autoradiographs (Eastman Kodak, Rochester, NY, USA) and scanned. The signal's intensity (including a blank region) was quantitated using the NIH Image J software. The immunoblot was treated in stripping buffer (Pierce, Thermo Fisher Scientific, Rockford, IL, USA) for $30 \mathrm{~min}$ and then re-probed with a mouse monoclonal antibody against $\beta$-actin (1:4,000; Sigma, St. Louis, MO, USA) to quantitate the expression of $\beta$-actin. Control and treatment values were corrected for blank values and normalized to their respective $\beta$-actin band intensity.

\section{Statistical Analysis}

Descriptive statistics, including means and SDs for continuous variables and frequencies for categorical variables, were calculated for FA and water groups. For the BBB pain score experiments, analyses were performed both cross-sectionally and longitudinally. In particular, we used a linear mixed effects model to assess how each individual animal progressed over the course of treatment. In addition, in assessing TH testing of injured animals treated with FA and water, a simple $t$ test (paired or 2-sample) was performed when such methods were appropriate and informative. For MMP2 experiments, a one-way analysis of variance model was utilized, where the null hypothesis that the group means of sham, control (water), and FA treatments are equal is tested globally. We investigated how well the model fits the data by reporting goodness-offit statistics, including R-squared measures, which describe the percentage of variation in the response that is explained by the model. Finally, we performed post-hoc analysis to assess the effects of pairwise comparisons between the groups (i.e., water vs. sham, FA vs. sham, and FA vs. water), using Tukey's honestly significant difference post-hoc test. All statistical analyses were performed using the 2-sided alpha significance level of 0.05 , with STATA version 14 software.

\section{Results}

\section{Locomotor Functional Recovery in Spinal \\ Cord-Injured Animals Treated with FA}

To determine whether FA administration after SCI improves function, we performed BBB scoring on injured animals treated with $80 \mu \mathrm{g} / \mathrm{kg}$ FA or with water for 3 days prior to injury and 17 days post CSCI. BBB scores obtained on a daily basis from days 0 to 18 post cSCI were analyzed using linear regression models. These analyses show highly significant differences between the FA and the water groups (Fig. 1a). BBB scores were also collected on days $0,7,14$, and 18 post cSCI. The analysis of these data showed significant differences between water (control) and FA groups over time (Fig. 1b). In a separate experiment, we injected the animals on a daily basis 3 days before and 14 days after injury, and the BBB scoring was done from day 0 through 42 days' post CSCI (on days 0 , $2,7,14,21,28,35$, and 42 ). The analysis of the data with a 2-sample $t$ test with equal variances assumption showed an overall statistically significant difference in BBB scores between animals on FA and those on water (Fig. 1c). Together, these data show that FA improves locomotor function during both the mid phase and the late phase of injury.

\section{Decreased NP in Spinal Cord-Injured Animals Treated with $F A$}

To determine whether FA administration after SCI decreases NP, we tested TH on injured animals treated with $80 \mu \mathrm{g} / \mathrm{kg}$ FA or with water, for 3 days prior to injury and 17 days post cSCI. The TH was measured on day 18 post cSCI. The results show significant differences between FA and control (water) groups, indicating that FA ameliorates NP after SCI (Fig. 2a). To determine whether FA administration after SCI decreases NP for a prolonged period of time, we tested $\mathrm{TH}$ on injured animals treated with $80 \mu \mathrm{g} / \mathrm{kg}$ FA or water for 3 days prior to injury and 14 days post cSCI on days $21,28,35$, and 42 . A paired $t$ test of pain 


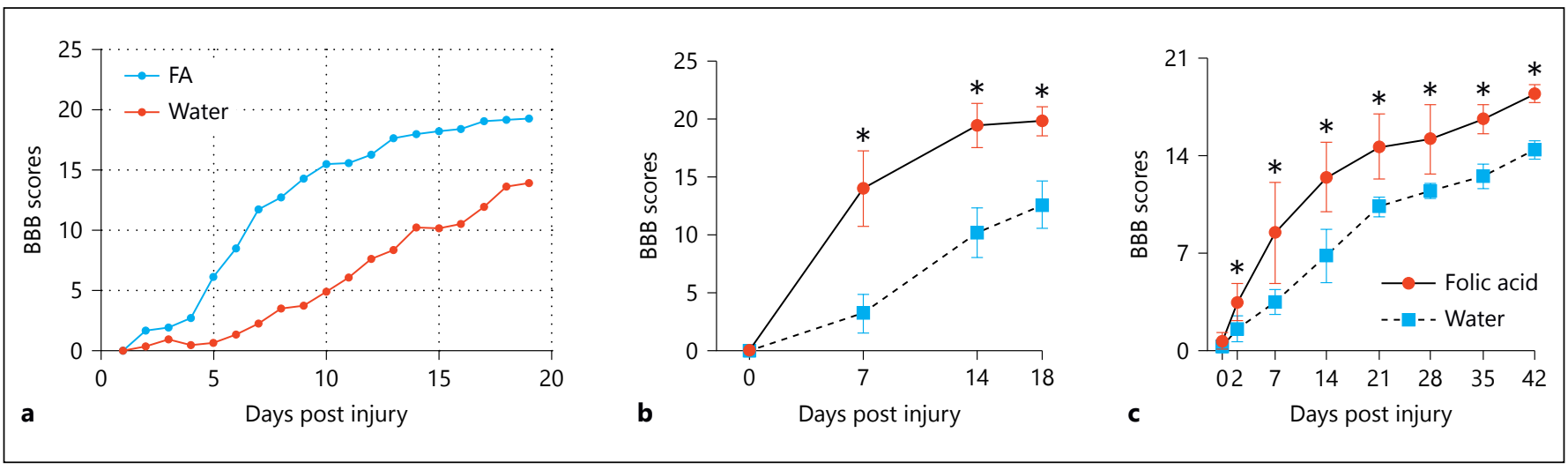

Fig. 1. Functional recovery and NP in animals treated with folic acid (FA) following cSCI. a BBB scores obtained on daily basis from days 0 to 18 post cSCI. The linear regression analysis showed significant difference between FA-treated group and the control (water treated) group. $n=6$ (control), $n=8$ (FA), $p<0.001$. b BBB scores obtained on days $0,7,14$, and 18 post cSCI. The mean BBB scores increased over time in the FA treated group. $n=6$ /group,
$* p<0.05$. c BBB scores from day 0 through day 42 post cSCI. The animals were treated with FA or water (control) daily 3 days before and 14 days after cSCI. The results showed significant differences in functional recovery between FA- and water-treated groups. Two-sample $t$ test with equal variances assumption, $n=6$ /group, $* p<0.05$. response by each of those groups revealed a highly statistically significant difference between FA- and water-treated groups on days 21,28 , and 35 (Fig. 2b). We also ran a mixed effect linear regression model that included treatment groups and time and in which the outcome is pain response so that we could investigate the pain responses of an animal in the FA group compared to the same type of animal in the water group - the inferences in our model were made about the animals in our groups rather than based on a population average. The correlations among responses for each individual animal arose from natural heterogeneity in regression coefficients across all the animals. In addition, we also tested if there is an interaction between treatment and time. The results show that animals in the FA-treated group responded 1.22 times higher for every unit increase in pain than a similar animal given water treatment and that there is no interaction between treatment and time; time is consistent with the profile plot (Fig. 2bii). Overall, the data show a higher response in the FA group compared to the water group. On the other hand, there is no statistical difference between the FA- and water-treated groups on day 42 (Fig. 2c) owing to the recovery during that time period.

\section{Decreased MMP2 Expression in Spinal Cord-Injured Animals Treated with FA}

To determine whether FA administration altered MMP2 expression, we tested MMP2 expression in spinal cord epicenter tissue from injured animals treated with
$80 \mu \mathrm{g} / \mathrm{kg}$ FA or with water for 3 days prior to injury and 17 days post CSCI. Western blot results from tissues harvested on day 18 or 42 post cSCI show significant decrease in MMP expression in tissues from injured animals treated with $80 \mu \mathrm{g} / \mathrm{kg}$ FA compared to the control (water; Fig. 3ai, ii and bi, ii).

\section{Discussion}

MMPs are endopeptidases known to play a role in the extracellular matrix degradation, immune response, pathogenesis, inflammation, cellular signaling, cell migration, tissue remodeling, and repair [24-26]. MMP induction following injury [27] is known to limit functional recovery after SCI [28]. MMPs have been reported to cause inflammation and NP after peripheral nerve injury [1]. Several studies have shown a relationship between DNA methylation and MMP expression and NP after CNS injury $[6,29,30]$. Here, in this paper, we show the effect of FA, a dietary supplement and key methylator of the CNS, on the expression of MMP2. Our results show that FA alters the expression of MMP2, alleviates $\mathrm{NP}$, and improves functional recovery after cSCI. This opens up a novel therapeutic avenue for managing SCIinduced NP and might throw light on a possible epigenetic mechanism in FA-induced recovery after SCI.

This study shows that MMP2 expression is significantly reduced by FA treatment 3 days pre-cSCI and 17 days 

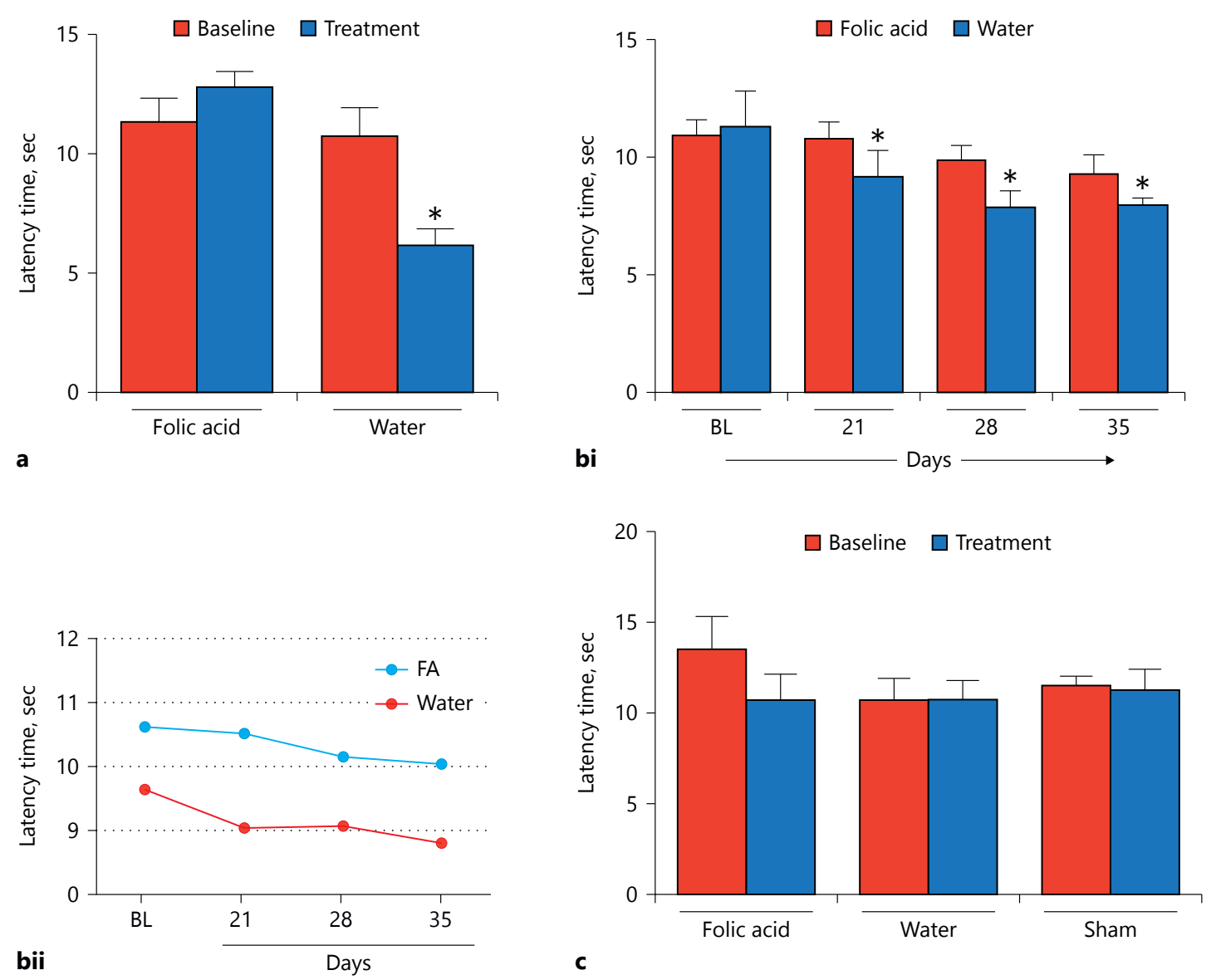

Fig. 2. Thermal hyperalgesia data from animals treated with folic acid (FA) following cSCI. a Treatments were given 3 days prior to injury and 17 days post injury, and the $\mathrm{TH}$ was performed on day 18 post $\mathrm{cSCI}$. The values are mean $\pm \mathrm{SE}, n=6$ /group, paired 2 tail test, ${ }^{*} p<0.0001$ (control vs. FA). bi Treatments were given 3 days prior to injury and 14 days post injury, and the TH was performed on days 21,28 , and 35 post cSCI. The values are mean \pm SE, $n=8$ (control), $n=7$ (FA), paired 2 tail test, ${ }^{*} p<0.0001$ (control vs. FA).

post cSCI. Earlier studies have shown that FA induces spinal axon regeneration and improves functional recovery after SCI partly via DNA methylation $[11,12]$. Studies have shown that intrathecal administration of DNA methyltransferase inhibitor following CCI results in the suppression of global increase in DNA methylation and $\mathrm{MeCP}$, alleviating mechanical allodynia and $\mathrm{TH}$ [6]. In this respect, the promoter region of 13 of 24 MMPs shows $\mathrm{CpG}$ islands with a potential for epigenetic regulation by
BL, baseline. bii A mixed effect linear regression model for the data in (bi), where the outcome is pain response and the treatment group and time in the model showed a significant difference between FA and water groups $(p=0.002)$. c Treatments were given 3 days prior to injury and 14 days post $\mathrm{CSCI}$, and the TH was performed on day 42 . The values are mean \pm SE, $n=6$ (water control), $n=5$ (FA), $n=2$ (sham control). There is no significant difference in latency between the FA and the water groups.

methylation [29]. Methylation contributes to the transcriptional activity of the MMP9 promoter, and the hypomethylation of MMP3 results in increased protein expression [30]. The role of FA in MMP2 methylation needs to be investigated further.

TH was decreased on day 18 post cSCI, which followed FA administration 3 days prior to cSCI and 17 days post cSCI (Fig. 2a). However, there is no significant difference in TH latency in FA-treated and control groups when ob- 


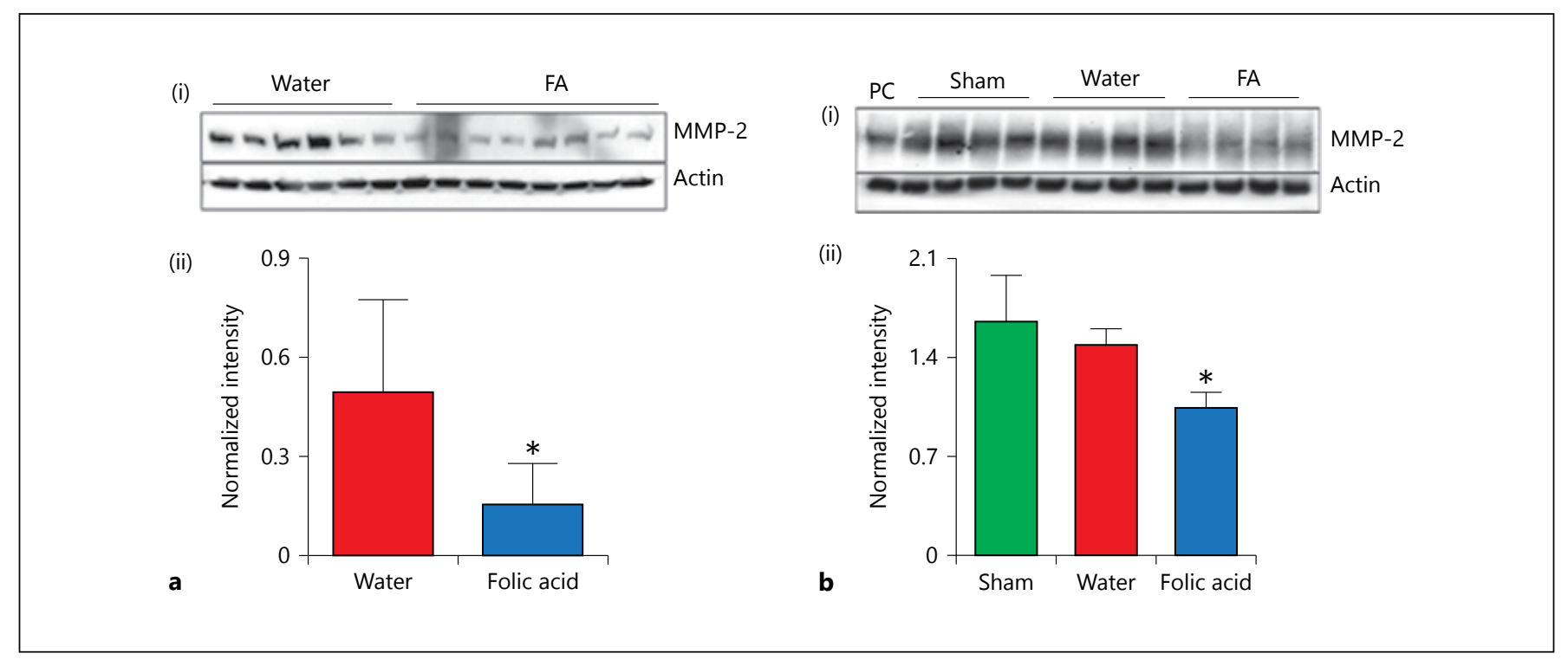

Fig. 3. Folic acid (FA) modulates the expression of MMP2, reduces NP, and induces functional recovery after SCI. a Western blot showing the expression of MMP-2 and $\beta$-actin on day 18 in the injured spinal cord tissue from FA-treated and control (water treated) rats (i). The quantitation of the data is given below (ii). Treatments were given 3 days prior to injury and 17 days post cSCI. The normalized intensity values are expressed as mean $\pm \mathrm{SE}, n=6$ (control), $n=8$ (FA), paired 2 tail test, ${ }^{*} p<0.01$ (control vs. FA).

served on day 42 (Fig. 2b). We have demonstrated previously that animals exhibiting elevated TH on days 21 and 28 post cSCI had higher levels of MMP2 in the injured spinal cord, as compared to those animals not exhibiting $\mathrm{TH}$ [5]. By lowering MMP2 expression, possibly by methylation with FA, we anticipate a reduced incidence of $\mathrm{TH}$. We hypothesize that ongoing methylation may be necessary to achieve effects on $\mathrm{TH}$. Other factors effecting MMP2 expression such as TIMP1 and TIMP3 are also targets for further research.

Regeneration of axons following CNS injury is inhibited by the formation of a glial scar and immature astrocytes. MMP2 has been reported to facilitate immature astrocytes to cross the proteoglycan rim across the immature glial bridges following use of 13 selective enzyme inhibitors [31]. It is also known that MMPs are integral to the formation of inhibitory glial scar and cytoskeleton-mediated astrocyte migration [32]. Experimental models of SCI suggest that MMP9 supports infiltration of inflammatory cells into the injured spinal cord and most likely contributes to early disruption of the blood-spinal cord barrier [28]. The spinal cord in response releases MMP9, initiating the aforementioned macrophage infiltration and degradation b Western blot showing the expression of MMP 2 and $\beta$-actin on day 42 in the injured spinal cord tissue from FA-treated and control (water treated) rats (i). The quantitation of the data is given below (ii). Treatments were given 3 days prior to injury and 17 days post cSCI. The normalized intensity values are expressed as mean \pm SE, $n=4$ /group, analysis of variance with Tukey's post hoc test, different letters represent statistical significance, ${ }^{*} p<0.05$. PC, positive control.

of myelin basic protein. Resulting exposure of the bare axon leads to increased sodium channel expression and ectopic hyperexcitability of afferent neurons, resulting in action potentials outlasting the stimulus that creates central sensitization, a common mechanism of NP after CNS injury [33]. However, our expression studies on MMP9 in injured spinal cords from animals treated with FA in the acute phase of injury (on days 1,3 , and 7 post cSCI) showed no significant difference from controls (data not shown). This might be attributed to a shorter FA treatment regimen used in this study or may be a result of a different transcriptional mechanism of MMP9 that is independent of folate. In this context, the contribution of FA to curb these mechanisms by mechanisms other than DNA methylation is yet another topic for further investigation.

The implications of FA supplementation in stimulating notch signaling, cell proliferation, and differentiation of neural stem cells have been reported $[34,35]$. Underlying mechanisms revealed a significant upregulation of Notch1 mRNA and protein expression, decline in expression of inflammatory proteins in nerve cells under hypoxia condition by preventing $\mathrm{Ca}^{2+}$ overload, and protective effect on nerve cells. Furthermore, a combination 
therapy of FA administered with adult neural stem cells resulted in a significantly improved nerve function by sustaining microenvironment homeostasis in the neurons of SCI rats [36].

\section{Conclusions}

The experiments described in this paper allowed us to partially define the role of MMP2 in NP and will serve as a foundation for further experiments. Use of dietary supplement FA to induce epigenetic modification of MMPs may be a novel therapeutic approach for dealing with NP after injury. This study will pave the way for follow-up clinical testing of the dietary supplement FA with current therapies to reduce patients suffering from SCI-induced NP.

\section{Acknowledgments}

The authors wish to thank Dr. Robert J. Dempsey, Chairman, Department of Neurological Surgery, for his constant encouragement during the study. Funding for this study was from Dr. Daniel
K. Resnick and Dr. Bermans J. Iskandar, Department of Neurological Surgery, University of Wisconsin School of Medicine and Public Health, Madison, WI, USA.

Emmanuel Sampene project is supported by the Clinical and Translational Science Award program, through the NIH National Center for Advancing Translational Sciences, grant UL1TR000427.

\section{Authorship Contributions}

Experiments were designed by G.S.M. and S.V.M., and performed by G.S.M., S.B., C.N., N.M., K.P., and L.L. Laboratory facilities/reagents and materials/analysis tools were provided by D.K.R., S.V.M., and N.H. Animal surgery work was undertaken by G.S.M., C.N., K.P., and L.L. Postsurgical care of experimental animals was undertaken by C.N., K.P., and L.L. Spinal cord tissue harvest was performed by S.B., C.N., and K.P., and Western blotting was by A.S., C.S., and N.M. Data analysis was performed by E.S., G.S.M., S.V.M., and N.H. The manuscript was written by G.S.M., S.V.M., D.K.R., and B.I.

\section{Disclosure Statement}

The authors declare that they have no competing interests.

\section{References}

1 Kawasaki Y, Xu ZZ, Wang X, Park JY, Zhuang ZY, Tan PH, Gao YJ, Roy K, Corfas G, Lo EH, Ji RR: Distinct roles of matrix metalloproteases in the early- and late-phase development of neuropathic pain. Nat Med 2008; 14 :331336.

2 Zhang H, Chang M, Hansen CN, Basso DM, Noble-Haeusslein LJ: Role of matrix metalloproteinases and therapeutic benefits of their inhibition in spinal cord injury. Neurotherapeutics 2011;8:206-220.

3 Pathak NN, Balaganur V, Lingaraju MC, More AS, Kant V, Kumar D, Kumar D, Tandan SK: Antihyperalgesic and anti-inflammatory effects of atorvastatin in chronic constriction injury-induced neuropathic pain in rats. Inflammation 2013;36:1468-1478.

4 Schomberg D, Miranpuri G, Duellman T, Crowell A, Vemuganti R, Resnick D: Spinal cord injury induced neuropathic pain: molecular targets and therapeutic approaches. Metab Brain Dis 2015;30:645-658.

5 Miranpuri GS, Schomberg DT, Alrfaei B, King KC, Rynearson B, Wesley VS, Khan N, Obiakor K, Wesley UV, Resnick DK: Role of matrix metalloproteinases 2 in spinal cord Injury-induced neuropathic pain. Ann Neurosci 2016;23:25-32.

6 Wang Y, Liu C, Guo QL, Yan JQ, Zhu XY, Huang CS, Zou WY: Intrathecal 5-azacytidine inhibits global DNA methylation and methyl- CpG-binding protein 2 expression and alleviates neuropathic pain in rats following chronic constriction injury. Brain Res 2011;1418:64-69.

7 Burzynski SR: Aging: gene silencing or gene activation? Med Hypotheses 2005;64:201208.

8 Hackanson B, Robbel C, Wijermans P, Lübbert M: In vivo effects of decitabine in myelodysplasia and acute myeloid leukemia: review of cytogenetic and molecular studies. Ann Hematol 2005;84(suppl 1):32-38.

9 Reichard JF, Puga A: Effects of arsenic exposure on DNA methylation and epigenetic gene regulation. Epigenomics 2010;2:87-104.

10 Chicoine E, Esteve PO, Robledo O, Van Themsche C, Potworowski EF, St-Pierre Y: Evidence for the role of promoter methylation in the regulation of MMP-9 gene expression. Biochem Biophys Res Commun 2002;297: 765-772.

11 Iskandar BJ, Nelson A, Resnick D, et al: Folic acid supplementation enhances repair of the adult central nervous system. Ann Neurol 2004;56:221-227.

12 Iskandar BJ, Rizk E, Meier B, et al: Folate regulation of axonal regeneration in the rodent central nervous system through DNA methylation. J Clin Invest 2010;120:1603-1616.

13 Resnick DK, Schmitt C, Miranpuri GS, Dhodda VK, Isaacson J, Vemuganti R: Molecular evidence of repair and plasticity following spinal cord injury. Neuroreport 2004;15:837839 .

14 DomBourian MG, Turner NA, Gerovac TA, Vemuganti R, Miranpuri GS, Türeyen K, Satriotomo I, Miletic V, Resnick DK: B1 and TRPV-1 receptor genes and their relationship to hyperalgesia following spinal cord injury. Spine (Phila Pa 1976) 2006;31:27782782.

15 Rajpal S, Gerovac TA, Turner NA, Tilghman JI, Allcock BK, McChesney SL, Miranpuri GS, Park SW, Resnick DK: Antihyperalgesic effects of vanilloid-1 and bradykinin-1 receptor antagonists following spinal cord injury in rats. J Neurosurg Spine 2007;6:420-424.

16 Park SW, Yi JH, Miranpuri G, Satriotomo I, Bowen K, Resnick DK, Vemuganti R: Thiazolidinedione class of peroxisome proliferator-activated receptor gamma agonists prevents neuronal damage, motor dysfunction, myelin loss, neuropathic pain, and inflammation after spinal cord injury in adult rats. J Pharmacol Exp Ther 2007;320:10021012.

17 Cramer SW, Baggott C, Cain J, Tilghman J, Allcock B, Miranpuri G, Rajpal S, Sun D, Resnick D: The role of cation-dependent chloride transporters in neuropathic pain following spinal cord injury. Mol Pain 2008;17; 4:36. 
18 Ahmed MM, Rajpal S, Sweeney C, Gerovac TA, Allcock B, McChesney S, Patel AU, Tilghman JI, Miranpuri GS, Resnick DK: Cannabinoid subtype- 2 receptors modulate the antihyperalgesic effect of WIN 55,212-2 in rats with neuropathic spinal cord injury pain. Spine J 2010;10:1049-1054.

19 Kim HT, Kim T, Novotny B, Khan N, Aksamit J, Siegel S, Miranpuri GS, Resnick DK: Thermal hyperalgesia assessment for rats after spinal cord injury: developing a valid and useful pain index. Spine J 2014;14:984-989.

20 Ahmed MM, Lee H, Clark Z, Miranpuri GS, Nacht C, Patel K, Liu L, Joslin J, Kintner D, Resnick DK: Pathogenesis of spinal cord injury induced edema and neuropathic pain: expression of multiple isoforms of wnk1. Ann Neurosci 2014;21:97-103.

21 Basso DM, Beattie MS, Bresnahan JC: A sensitive and reliable locomotor rating scale for open field testing in rats. J Neurotrauma 1995; $12: 1-21$.

22 Hargreaves K, Dubner R, Brown F, Flores C, Joris J: A new and sensitive method for measuring thermal nociception in cutaneous hyperalgesia. Pain 1988;32:77-88.

23 Lowry OH, Rosebrough NJ, Farr AL, Randall RJ: Protein measurement with the Folin phenol reagent. J Biol Chem 1951;193:265-275.
24 de Castro RC Jr, Burns CL, McAdoo DJ, Romanic AM: Metalloproteinase increases in the injured rat spinal cord. Neuroreport 2000;11: 3551-3554.

25 Mott JD, Werb Z: Regulation of matrix biology by matrix metalloproteinases. Curr Opin Cell Biol 2004;16:558-564.

26 Esposito E, Genovese T, Caminiti R, Bramanti P, Meli R, Cuzzocrea S: Melatonin regulates matrix metalloproteinases after traumatic experimental spinal cord injury. J Pineal Res 2008;45:149-156.

27 Buss A, Pech K, Kakulas BA, Martin D, Schoenen J, Noth J, Brook GA: Matrix metalloproteinases and their inhibitors in human traumatic spinal cord injury. BMC Neurol 2007;7:17.

28 Noble LJ, Donovan F, Igarashi T, Goussev S, Werb Z: Matrix metalloproteinases limit functional recovery after spinal cord injury by modulation of early vascular events. J Neurosci 2002;22:7526-7535.

29 Chernov AV, Strongin AY: Epigenetic regulation of matrix metalloproteinases and their collagen substrates in cancer. Biomol Concepts 2011;2:135-147.

30 Couillard J, Demers M, Lavoie G, St-Pierre Y: The role of DNA hypomethylation in the control of stromelysin gene expression. Biochem Biophy Res Comm 2006;342:1233-1239.
31 Filous AR, Miller JH, Coulson-Thomas YM, Horn KP, Alilain WJ, Silver J: Immature astrocytes promote CNS axonal regeneration when combined with chondroitinase ABC. Dev Neurobiol 2010;70:826-841.

32 Chattopadhyay S, Myers RR, Janes J, Shubayev V: Cytokine regulation of MMP-9 in peripheral glia: implications for pathological processes and pain in injured nerve. Brain Behav Immun 2007;21:561-568.

33 Kobayashi K, Yamanaka H, Fukuoka T, Dai Y, Obata K, Noguchi K: P2Y 12 receptor upregulation in activated microglia is a gateway of p38 signaling and neuropathic pain. J Neurosci 2008;28:2892-2902.

34 Liu H, Huang GW, Zhang XM, Ren DL, X Wilson J: Folic acid supplementation stimulates notch signaling and cell proliferation in embryonic neural stem cells. J Clin Biochem Nutr 2010;47:174-180.

35 Zhang X, Liu H, Cong G, Tian Z, Ren D, Wilson JX, Huang G: Effects of folate on notch signaling and cell proliferation in neural stem cells of neonatal rats in vitro. J Nutr Sci Vitaminol (Tokyo) 2008;54:353-356.

36 Zhang C, Shen L: Folic acid in combination with adult neural stem cells for the treatment of spinal cord injury in rats. Int J Clin Exp Med 2015;8:10471-10480. 